\title{
Wireless multimedia surveillance networks
}

Multimedia Tools and Applications gratefully acknowledges the editorial work of the scholars listed below on the special issue entitled "Wireless Multimedia Surveillance Networks" (SI 1090).

Of 57 papers submitted to this issue, 27 were eventually accepted after a stringent peer review process.

\section{Corresponding Guest Editor}

\section{Prof. Seungmin Rho}

Sungkyul University, South Korea

Email: smrho@sungkyul.edu

\section{Guest Editors}

\section{Dr Yu Chen}

Binghamton University, State University of New York, USA

Email: ychen@binghamton.edu

Publisher's note Springer Nature remains neutral with regard to jurisdictional claims in published maps and institutional affiliations. 